\title{
SEGURO DECENAL \\ Reflexión sobre el Seguro Decenal como oportunidad del mercado asegurador colombiano ante las necesidades del Sector Constructor*
}

\author{
INHERENT DEFECT INSURANCE POLICY \\ Insurance Market Challenges and opportunities \\ in the Construction Industry
}

\author{
FERNANDO LOMBANA SILVA** \\ CARLOS EDUARDO GONZÁLEZ TRIVIÑO ${ }^{* * *}$ \\ Fecha de recepción: 30 de mayo de 2017 \\ Fecha de Aceptación: 15 de junio de 2017 \\ Disponible en linea: 30 de junio de 2017
}

\section{Para Citar este artículo/To cite this article}

Lombana Silva, Fernando \& González Triviño, Carlos Eduardo, Seguro decenal: Reflexión sobre el seguro Decenal como oportunidad del mercado asegurador colombiano ante las necesidades del sector constructor, 46 Rev.Ibero-Latinoam.Seguros, 189-212 (2017). https://doi.org/10.11144/ Javeriana.ris46.sdrs doi:10.11144/Javeriana.ris46.sdrs

* Artículo Técnico Económico

** Ingeniero Eléctrico, Universidad de Los Andes. Especialización en Gerencia Estratégica, Universidad de La Sabana. Vicepresidente Técnico de La Previsora S.A Compañía de Seguros. Bogotá, Colombia. Calle 57 \#9-07 Piso 7, Contacto: fernando.lombana@previsora.gov.co, felosi63@hotmail.com

*** Ingeniero Químico, Universidad Nacional de Colombia. Especialización en Seguros, Universidad Externado de Colombia. Gerente de Seguros Generales y Ramos Técnicos de La Previsora S.A Compañía de Seguros. Bogotá, Colombia. Calle 57 \# 9 - 07 Piso 7, Contacto: carlos.gonzalez@, previsora.gov.co, carlosegonzalezt@gmail.com 


\section{RESUMEN}

Historia, reflexiones y estudio técnico de la póliza decenal como una oportunidad para el mercado colombiano en búsqueda de posible solución para los compradores de soluciones de vivienda, para dar tranquilidad y garantizar la estabilidad de la construcción, encaminado a mitigar los errores de diseño, deficiencia de materiales y fallas en la estructura en la iniciativa de la ley 1796 de 2016 "ley de vivienda segura".

Palabras clave: Constructor; ley; patrimonio; protección; responsabilidad; seguro decenal; vivienda. 


\begin{abstract}
Upon the enactment of Law 1796 of 2016, the manuscript presents thoughts on decennial liability insurance as a chance for the Colombian market to seek an affordable solution for home buyers, providing stability and safety in construction issues and mitigating design, materials flaws and structure failures.
\end{abstract}

Keywords: Builder; Law; Worth; Protection; Liability; Inherent Defect; Homes

\title{
SUMARIO
}

1. ANTECEDENTES - Imperio romano - Francia - España - Latinoamérica Resto del Mundo - 2. ECONOMÍA Y DINÁMICA DE LA CONSTRUCCIÓN EN COLOMBIA - 3. NORMATIVIDAD OBLIGACIONES DEL CONSTRUCTOR - 4. LOS SEGUROS DE CONSTRUCCIÓN EN COLOMBIA. - Seguros obligatorios en Colombia - Seguros voluntarios en Colombia - 5. ANTECEDENTES SEGURO DECENAL EN COLOMBIA Edificio Space un detonante a la creación de la ley - Causas probables del colapso de la Etapa 6 - 6. SEGURO DECENAL - Coberturas - Coberturas adicionales - Exclusiones - Generalidades - Conclusiones del estudio - 7. Consideraciones sobre el Seguro Decenal - 8. GESTIÓN DE LA OCT - 9. CONCLUSIONES - 10. BIBLIOGRAFÍA 


\section{ANTECEDENTES}

\section{Imperio romano}

El mundo romano vio desarrollarse una sociedad fuertemente urbana. El espacio limitado de las ciudades generó la necesidad de buscar solventar la falta de suelo con la construcción en vertical, de edificios cada vez más altos. Para limitar los abusos, y los riesgos, el legislador romano tuvo la preocupación, de forma muy temprana, de tener en consideración estas condiciones. Por esta razón, los romanos tuvieron que legislar, ya de forma temprana, sobre la forma de construcción, la altura edificable máxima y las servidumbres que debían afectar a los edificios, con tal de garantizar seguridad para los habitantes y viabilidad urbanística.

En cualquier caso, en el conjunto de normas que hoy llamaríamos urbanísticas, se pueden distinguir tres grandes grupos de regulaciones:

1) La distancia entre los edificios,

2) La altura máxima permitida

3) La conservación y reparación de los edificios.

\section{Francia}

Después de la legislación romana que en buena medida se adoptó en muchas partes del mundo y cuyas directrices aún se mantienen en las normas actuales, se puede mencionar el código civil francés o "código napoleónico" promulgado el 21 de Marzo de 1804 y aún vigente. Dentro de sus artículos incluyó lo relacionado con la tierra, la identificación de los diferentes tipos de bienes, muebles e inmuebles, y las normas de usufructo y construcción de las propiedades y las servidumbres.

La responsabilidad de los constructores en Francia tiene un largo recorrido puesto que data del Código Civil de 1804. El sistema francés ha querido garantizar al propietario de un inmueble una elevada protección, durante diez años, frente a daños considerables que puedan aparecer después de la construcción de la obra. 
La responsabilidad legal decenal se contempla en los artículos 1792 y 1792-2 del Código Civil francés; consagra el principio de presunción de responsabilidad por un periodo de diez años sin posibilidad de reducción.

En Francia, el seguro obligatorio generalizado se destina a garantizar la protección física y financiera del consumidor. El sistema francés de seguro de construcción, instaurado desde 1978, bajo la conocida Ley Spinetta.

El seguro decenal deberá haberse contratado antes que comience la obra. Al inicio de cualquier obra tendrá que estar en condiciones de justificar el haber suscrito un contrato de seguro que cubra dicha responsabilidad.

En Francia se trata de un seguro obligatorio, aun así las compañías que lo proponen compiten entre sí y las tarifas son libres; cada aseguradora consultada fija la cotización en función de los elementos del informe de definición de riesgos.

\section{España}

En España, la Ley 38 de 1999 o Ley de Ordenación de la Edificación(LOE) determina en su exposición de motivos que debido al aumento de la demanda de calidad de las edificaciones, la garantía que deba constituirse con el objeto de proteger a los usuarios apunte no solo a los requisitos técnicos de lo construido sino también la constitución de un seguro de daños o de caución; determinándose, en el mismo sentido, que para el caso de edificios de vivienda, el constructor debe suscribir en forma obligatoria el seguro de daños materiales que ampare aquellos perjuicios ocasionados por una deficiente ejecución de la obra y un seguro que escude el detrimento causado por el incumplimiento de las condiciones de habitabilidad o que afecten la seguridad estructural entre los tres (3) y diez (10) años, requisitos que se constituyen como indispensables para el otorgamiento de las correspondientes escrituras públicas y liquidación de las sociedades correspondientes.

En concordancia con lo señalado, el artículo 19 de la Ley de Ordenación de la Edificación (LOE) establece la constitución de garantías por daños materiales provocados por vicios y defectos en la construcción así: "Artículo 19. Garantías por daños materiales ocasionados por vicios y defectos de la construcción. 1. El régimen de garantías exigibles para las 
obras de edificación comprendidas en el artículo 2 de esta Ley se hará efectivo de acuerdo con la obligatoriedad que se establezca en aplicación de la disposición adicional segunda, teniendo como referente a las siguientes garantías: a) Seguro de daños materiales o seguro de caución, para garantizar, durante un año, el resarcimiento de los daños materiales por vicios o defectos de ejecución que afecten a elementos de terminación o acabado de las obras, que podrá ser sustituido por la retención por el promotor de un 5 por 100 del importe de la ejecución material de la obra. b) Seguro de daños materiales o seguro de caución, para garantizar, durante tres años, el resarcimiento de los daños causados por vicios o defectos de los elementos constructivos o de las instalaciones que ocasionen el incumplimiento de los requisitos de habitabilidad del apartado 1, letra c), del artículo 3. c) Seguro de daños materiales o seguro de caución, para garantizar, durante diez años, el resarcimiento de los daños materiales causados en el edificio por vicios o defectos que tengan su origen o afecten a la cimentación, los soportes, las vigas, los forjados, los muros de carga u otros elementos estructurales, y que comprometan directamente la resistencia mecánica y estabilidad del edificio”.

\section{Latinoamérica}

Por su parte, en México, la Ley Federal de Protección al Consumidor establece en su artículo 73 Quáter, que todo bien inmueble que se ofrezca al consumidor deberá contar con una garantía que no podrá ser inferior a cinco (5) años cuando se trate de temas estructurales, tres (3) años por impermeabilización y un (1) año para los demás elementos, contándose los anteriores plazos a partir de la entrega efectiva del inmueble. En Chile, la Ley General de Urbanismo y Construcciones de 1975, cuya última reforma se efectuó el 5 de noviembre de 2013, establece entre otras, las responsabilidades y sanciones de los profesionales y particulares cuando ejerzan funciones de urbanización y construcción, fijando a través de una Ordenanza General, reglamentos sobre los estándares técnicos de diseño y construcción.

\section{Resto del mundo}

Otros países como Bélgica, Holanda, Alemania, Qatar y Emiratos Árabes Unidos han incluido en sus ordenamientos jurídicos responsabilidades 
del constructor de tipo legal, similares a la consagrada por el numeral 3 del Artículo 2060 del Código Civil.

\section{ECONOMÍA Y DINÁMICA DE LA CONSTRUCCIÓN EN COLOMBIA}

El desarrollo de las políticas públicas del gobierno en materia de vivienda especialmente en programas de vivienda de interés social (VIS) ha generado una muy buena dinámica. . La vivienda en Colombia y la construcción van de la mano y son protagonistas del eje financiero, con el impulso de una inversión de 1,6 billones de pesos para el sector garantizados por el Ministerio de Hacienda hasta el año 2026 con recursos por 6,9 billones.

La visión de futuro de la vivienda en Colombia se debe apalancar el crecimiento de este sector especialmente al segmento de interés social para dinamizar la economía nacional y como eje fundamental de una industria en crecimiento y florecimiento.

De otro lado, con la aprobación de $\$ 428.000$ millones se permitirá financiar 25.000 nuevos cupos a la tasa de interés para familias de estrato medio interesadas en adquirir vivienda nueva lo que da también una importancia múltiple a los estratos 3 y 4 dando dinámica de igual forma a este sector, siendo Bogotá la que impulsa estos indicadores pues el gremio de la construcción anunció crecimientos de 28\%,14\%, $10 \%$ en los lanzamientos de ventas y licitaciones pues en las cantidades de unidades vendidas se espera tener crecimientos de cercanos al $13 \%$ superando los años anteriores.

De igual forma, la dinámica de la construcción frente a la reforma tributaria, se sustenta en su aporte a la economía con el balance positivo del año 2016 y las proyecciones muy positivas para el año 2017. La cámara colombiana de la construcción (CAMACOL) proyecta que el sector de la construcción crecerá el 4\% en 2017.

En Colombia, cada vez se construyen más inmuebles para usos comerciales y empresariales, estas nuevas ofertas traerán beneficios en términos de ubicación, de estructura y de diseño, pues la industria de la construcción 
motiva para el 2017 en espera de apertura de nuevos centros comerciales en 16 ciudades con más de 565.000 metros cuadrados incrementándose los 214 que ya operan en la actualidad según estadísticas de la asociación de centros comerciales de Colombia (ACECOLOMBIA). En adición, este crecimiento de la industria de la construcción en Colombia obedece a cuatro leyes del ciclo inmobiliario: expansión, sobreoferta, recesión y recuperación.

El año pasado la economía cae hacia la desaceleración pero sostenida por el sector financiero 5\% anual que aporto poco más de la mitad del valor agregado y en menos soporte el sector de la construcción con 3,5\% anual. En total el crecimiento total del 2016 fue del 2\% que excedió los pronósticos de $1,8 \%$.

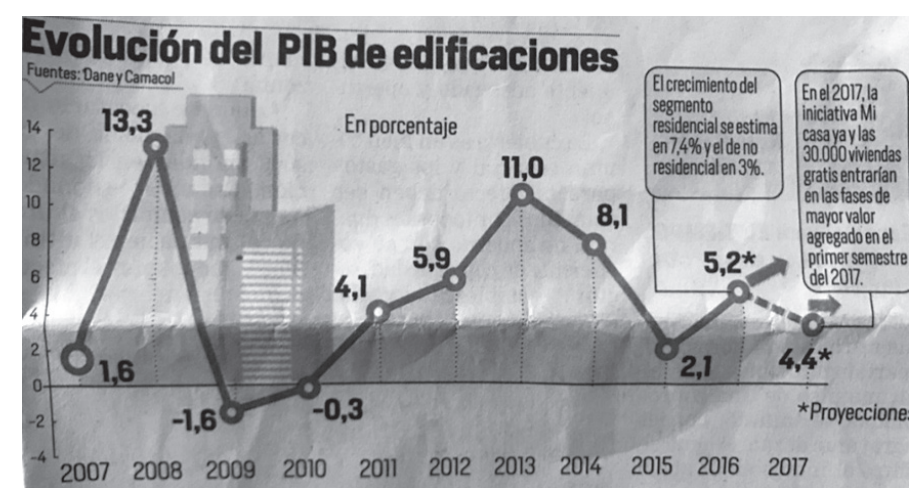

Imagen 1. Gráfico de evolución del PIB de Edificaciones en Colombia desde el 2007 al 2017 (Flórez, La dinámica del sector edificador, en manos de la reforma tributaria ,2016)

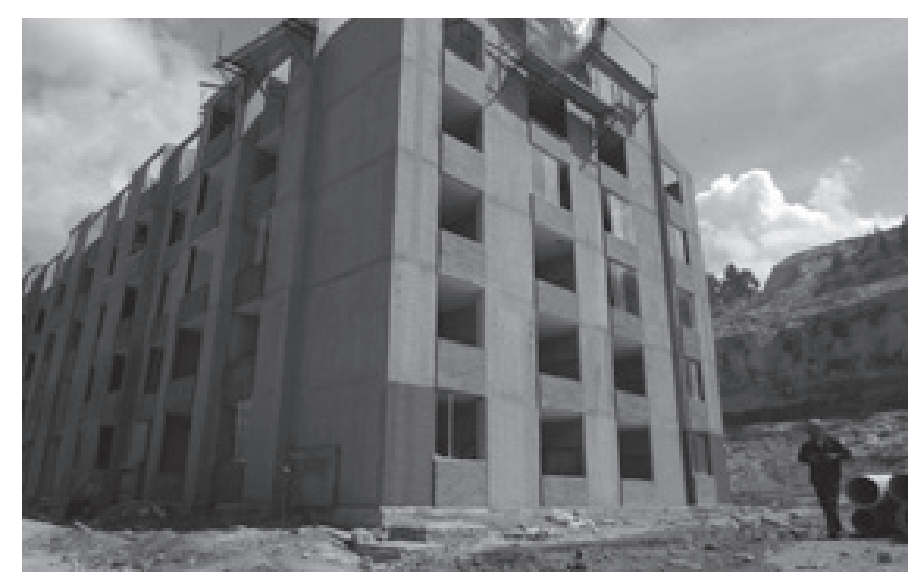

Imagen 2. Fotografía de construcción de vivienda de interés social (Vivienda, 2016) 


\section{NORMATIVIDAD OBLIGACIONES DEL CONSTRUCTOR}

Gran parte de los proyectos urbanísticos en el país, tienen como génesis la celebración de contratos de compraventa, fiducia, colaboración empresarial, entre otros, en virtud de los cuales los propietarios del suelo entregan la tenencia de los inmuebles a un constructor, quien será el encargado de desarrollar por su cuenta y riesgo el proyecto constructivo. En efecto, a quien despliega la actividad del proceso constructivo de edificaciones, además de aplicarse las normas generales de responsabilidad, le resultan aplicables una serie de normas especiales que para la construcción de una edificación comprende el Código Civil Colombiano.

Frente al caso específico de la construcción de edificaciones, el Código Civil en su artículo 2060 establece:

“ARTÍCULO 2060. Los contratos para construcción de edificios, celebrados con un empresario que se encarga de toda la obra por un precio único prefijado, se sujetan además a las reglas siguientes:

1. El empresario no podrá pedir aumento de precio, a pretexto de haber encarecido los jornales o los materiales, o de haberse hecho agregaciones o modificaciones en el plan primitivo; salvo que se haya ajustado un precio particular por dichas agregaciones o modificaciones.

2. Si circunstancias desconocidas, como un vicio oculto del suelo, ocasionaren costos que no pudieron preverse, deberá el empresario hacerse autorizar para ellos por el dueño; y si éste rehúsa, podrá ocurrir al juez o prefecto para que decida si ha debido o no preverse el recargo de obra, y fije el aumento de precio que por esta razón corresponda.

3. Si el edificio perece o amenaza ruina, en todo o parte, en los diez años subsiguientes a su entrega, por vicio de la construcción, o por vicio del suelo que el empresario o las personas empleadas por él hayan debido conocer en razón de su oficio, o por vicio de los materiales, será responsable el empresario; si los materiales han sido suministrados por el dueño, no habrá lugar a la responsabilidad del empresario sino en conformidad al artículo 2041, <sic 2057> inciso final”. 
La garantía decenal como obligación contractual está contenida en el artículo 2060, numeral tercero del Código Civil, y consiste en que el empresario se obliga para con el adquirente de la construcción a responder por los daños y perjuicios que se causen durante los diez años siguientes a la entrega de la construcción, por vicios de la construcción o del suelo que dicho empresario haya debido conocer en razón de su profesión u oficio, o por aquellos vicios en los materiales que el haya suministrado (tratándose de contratos de construcción por administración delegada), o le haya entregado el dueño de la obra (tratándose de contratos de construcción por empresa) y que el haya debido conocer por su profesión u oficio.

Por su parte, el artículo 104 de la Ley 1480 de 2011(Estatuto del Consumidor) establece una responsabilidad objetiva, en este caso para el empresario, pues basta probar el daño en la edificación y se presumirá la responsabilidad del mismo.

Con base en dicho artículo, se ha considerado que el tercero adquirente de la edificación, fundado en la garantía decenal podría reclamar del empresario constructor los daños sufridos cuando el edificio "perece o amenaza ruina" como consecuencia de los vicios de la construcción, del suelo o de los materiales, por cuanto dicha garantía se activa cuando el edificio perece o amenaza ruina, en todo o en parte en 10 años siguientes a su entrega, causados por los vicios referidos.

En el caso específico de los bienes inmuebles, además de las disposiciones antes enunciadas sobre los contratos de compraventa de bienes inmuebles y la responsabilidad civil por las actividades de la construcción, el Estatuto del Consumidor ha señalado una garantía legal que comprende la estabilidad de la obra por diez (10) años, y para los acabados un (1) año. El Decreto 735 de 2013, establece un procedimiento especial para hacer efectiva la garantía sobre bienes inmuebles bien para la reposición, sustitución o devolución del dinero por el producto comprado. 


\section{LOS SEGUROS DE CONSTRUCCIÓN EN COLOMBIA}

\section{Seguros obligatorios en Colombia}

\section{El Seguro de Calidad y Estabilidad de la Vivienda Nueva-SECAL-}

En Colombia, los regímenes que se han adoptado para mitigar los riesgos asociados a la actividad de la construcción se fundamentan principalmente en la responsabilidad legal, la garantía legal y los seguros obligatorios, siendo éstos últimos de aplicación en nuestro país:

El artículo 64 de la Ley 9 de 1989 reglamentado por el Decreto 3042 de 1989, obligaba a todo vendedor de vivienda nueva a garantizar la estabilidad por un lapso de tres (3) años, y la buena calidad de la vivienda por un período de dos (2) años, contados a partir del momento de la primera venta:

“Artículo 64".- Todo vendedor de vivienda nueva estará obligado a constituir una póliza para garantizar la estabilidad y la buena calidad de la vivienda. El notario público ante quien se efectúe la venta exigirá la protocolización de una copia de la póliza en la escritura correspondiente."

El seguro tenía por objeto indemnizar la reparación de los daños que sufriera el inmueble asegurado como consecuencia de la ausencia de calidad o estabilidad, a fin de restituir el inmueble asegurado a las condiciones de calidad y estabilidad técnicamente requeridas, incluyendo las demoliciones o desmontajes necesarios.

El valor asegurado se determinaba en función del precio de venta, el cual se reajustaba automáticamente de acuerdo al índice nacional de precios para el consumidor certificado por el DANE.

Tal disposición, fue subrogada por el artículo 40 de la Ley 3 de 1991 así:

“Artículo 40.- El artículo 64 de la Ley 9 de 1989, quedará así:

El Gobierno Nacional reglamentará las normas mínimas de calidad de la vivienda de interés social, especialmente en cuanto a espacio, servicios públicos y estabilidad de la vivienda". 
En virtud de un juicio de constitucionalidad realizado al artículo 40 de la Ley 3 de 1991, la Corte Constitucional en un fallo que armoniza las disposiciones que en el ordenamiento colombiano desarrollan el derecho a la vivienda digna, declaro exequible el artículo 40 de la Ley $3^{\text {a }}$ de 1991, en el entendido que, dentro de las condiciones mínimas de la vivienda de interés social, los vendedores están obligados a constituir una póliza de calidad y estabilidad de los inmuebles que enajenan.

\section{Seguros voluntarios en colombia}

\section{Seguro Todo Riesgo Constructor}

Así mismo, ha hecho carrera en el Sector Edificador la constitución voluntaria de seguros, como por ejemplo el seguro "Todo riesgo constructor".

Este seguro, ampara durante su vigencia los bienes contra las pérdidas o daños que sufran de manera súbita, accidental e imprevista, por la realización de alguno de los riesgos o eventos amparados, mientras tales bienes se hallen en la construcción. Los amparos cubiertos por ésta póliza, así como las exclusiones, dependen del producto que ofrezca cada aseguradora, resaltándose en la mayoría de los casos la exclusión de errores de diseño.

\section{Seguro de responsabilidad civil extracontractual}

Este seguro cubre los perjuicios patrimoniales que cause el asegurado con motivo de la responsabilidad civil en que incurra de acuerdo con la ley colombiana como consecuencia de daños a bienes de terceros y/o lesiones o muerte a personas causados por hechos accidentales, súbitos, repentinos e imprevistos, imputables a él, ocurridos durante la vigencia del seguro.

\section{Seguro de responsabilidad civil profesional para arquitectos e ingenieros}

Ampara daños y/o costos por reclamaciones propias y de terceros por causa de un acto erróneo, incluyendo actos de contratistas y subcontratistas en la prestación de sus servicios profesionales. 


\section{ANTECEDENTES SEGURO DECENAL EN COLOMBIA}

El desplome de la torre 6 del edificio Space de Medellín que dejo un saldo de 12 muertes, marco una huella en la historia de la construcción de viviendas en Colombia que dio origen al impulso para la creación de una nueva ley que impacta directamente sobre la vigilancia y control de las Edificaciones y la protección sobre los propietarios en caso de un colapso. La ley 1796 de 2016 conocida como la ley de vivienda segura entro en vigencia el pasado 13 de julio de 2016 puso su reglamentación de los mecanismos para cubrir este tipo de daños pero aun esta en reglamentación y principalmente el tema de seguros aún está en la incertidumbre, pues aunque ya existe en el mercado una alternativa mediante una póliza de seguro llamada "Decenal" La Cámara Colombiana de la Construcción (CAMACOL) manifiesta que no puede ser el único mecanismo para resarcir el perjuicio sobre las víctimas, pero creemos que la mejor opción es la póliza de seguros de la cual nos ocuparemos más adelante en este artículo.

\section{Edificio Space un detonante a la creación de la ley}

El día 12 de octubre de 2013 a las 20:20 horas se reportó el colapso de una parte del Edificio Space ubicado en la Carera 24D No. 10E-120 en la ciudad de Medellín, construido y gerenciado por la constructora Lérida CDO. La construcción del mencionado Edificio se llevó acabo en 6 etapas diferentes, pero se considera el licenciamiento como un solo Edificio, con la característica que las 6 etapas presentan diferentes números de pisos entre sí, pero la última etapa (etapa 6) la del colapso, era la de mayor altura con 23 pisos, 4 sótanos ( 2 niveles de parqueaderos y 2 niveles de zona social).

La mencionada etapa, tras presentar notorios problemas en sus estructuras, fue evacuada el día 11 de octubre de 2013 por orden del departamento administrativo de gestión de riesgos de desastres (DAGRD) pero posterior el día 12 de octubre de 2016, la etapa 6 colapsa con la fatal perdida de 12 vidas humanas, la mayoría trabajadores que estaban interviniendo la estructura de la torre afectada. En este orden e ideas, la alcaldía de Medellín contrata a la universidad de los andes en la facultad de ingeniería civil para la realización de estudios, evaluaciones diagnós- 
ticos y recomendaciones pertinentes a elaboración de conceptos técnicos con relación al cumplimiento de norma técnica aplicables a procesos de diseño, cimentación, estructura, y elementos no estructurales, de igual forma a la elaboración de concepto general del proyecto, sus deficiencias, la realización de estudios técnicos de detalle para conceptuar sobre la causa más probable y el concepto técnico sobre las decisiones relacionadas con la seguridad y funcionalidad de las mismas.

\section{Conclusiones del estudio}

Para efectos estructurales y de sismo resistencia, el edificio Space construido de las etapas 1-6 debe considerarse como una sola estructura de resistencia ante fuerzas gravitacionales y sísmicas horizontales de tal forma que el estudio concluye:

1. El proyecto del edificio SPACE no cumplió con requisitos básicos de la norma NSR-98.

2. El proyecto del edificio SPACE por incumplir la norma NSR-98 presentó graves deficiencias en las condiciones estructurales y de sismo resistencia.

3. El colapso de la etapa 6 sumado a la demolición de la etapa 5 no garantizaban la que edificación que se mantenía en pie no presentara un alto riesgo de colapso.

4. El proyecto de edificio Space no cumple con una serie de requerimientos básicos, establecidos en la normativa moderna para diseño y construcción de edificios.

5. Los parámetros de diseño sísmico no están claramente definidos.

6. La estructura presento deficiencias fundamentales como, alta irregularidad en planta, falta de redundancia estructural, placas de entrepiso de muy poca rigidez, ausencia de un diafragma rígido y falta de conectividad entre elementos estructurales principales a través de diafragma y elementos estructurales verticales deficientes en términos de sección y de cantidad de esfuerzo. 


\section{Causas probables del colapso de la Etapa 6}

Con toda la información disponible, y dado los diferentes análisis y conclusiones del estudio llevado acabo, el colapso de la etapa 6 del edificio Space está asociado a una causa primaria y una serie de factores detonantes que da como conclusión la falta de capacidad de las columnas principales de la edificación, para resistir cargas actuantes debido al peso de la estructura propia y de las cargas de servicio impuestas. Los efectos de la distribución progresiva de cargas y altas excentricidades generadas por asentamientos diferenciales registrados en las columnas principales y la falla de la columna S3, los altos niveles de esfuerzos en elementos estructurales principales como lo eran las columnas que conllevo a deformaciones excesivas con la posibilidad de deformación excesiva, los trabajos de intervención estructural que se estaban realizando que evidenciaron instalación de elementos de refuerzo metálico, la eventual falla de la columna cortante de las vigas principales del edificio en los niveles críticos y/o la falla a compresión de los muros de mampostería ante la distribución de cargas que se generó a consecuencia de los asentamientos diferenciales especialmente a la falla de la columna S3.

Podemos resumir que la falla se basa en una deficiente capacidad de los elementos estructurales como lo es las columnas del edificio, columnas mal dimensionadas para el nivel de cargas que debía trasmitir con

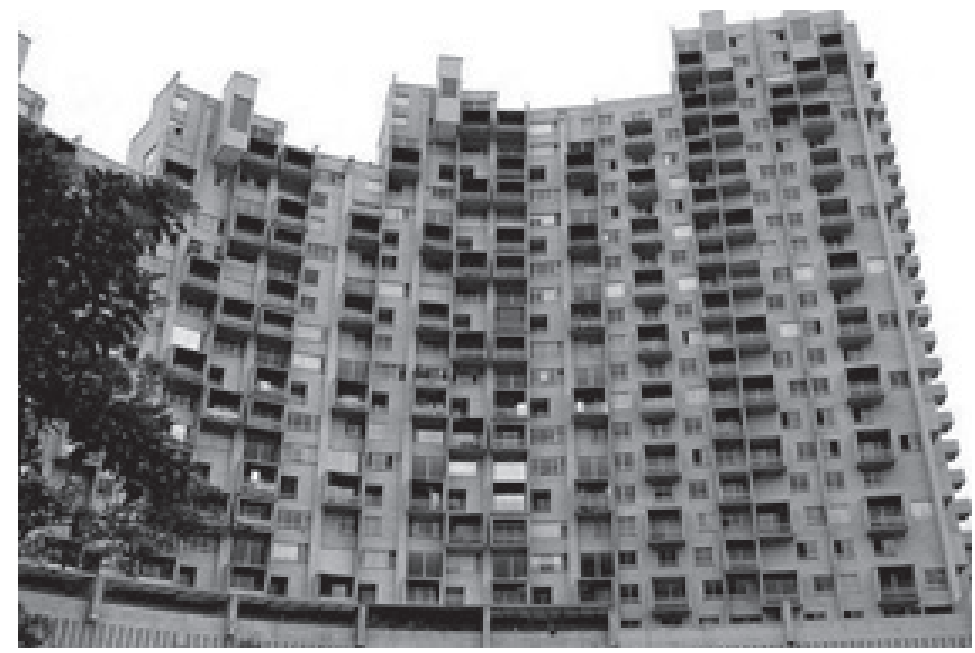

Imagen 3. Edificio Space antes de su caída (COLPRENSA, 2016) 
la consecuencia de aparición de problemas que se empiezan a evidenciar desde meses antes del colapso manifestándose a través de grietas, asentamientos importantes en el edificio y en las placas, y en una falla concentrada en una de las columnas principales de la construcción que fue el detonante principal del colapso con las consecuencia ya conocidas. No obstante lo anterior y a juicio de los expertos de la mencionada universidad, la estructura del edificio SPACE, de haberse diseñado cumpliendo la totalidad de los requisitos aplicables a la ley 400 de 1997 y sus decretos reglamentarios (NSR-98), la etapa 6 no hubiese presentado el colapso que se presentó bajo las condiciones impuestas.

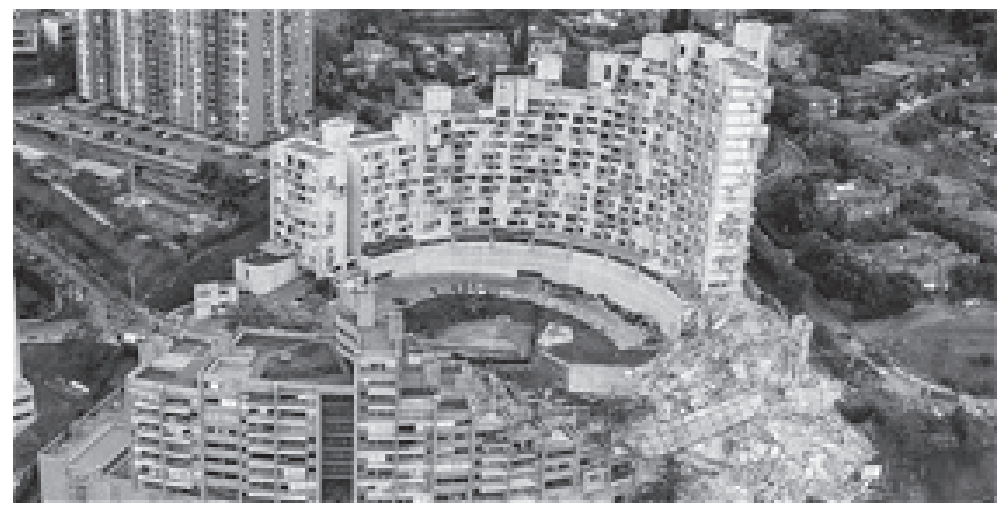

Imagen 4. Vista superior de Edificio Space luego de su caída (MEDELLÍN, 2014)

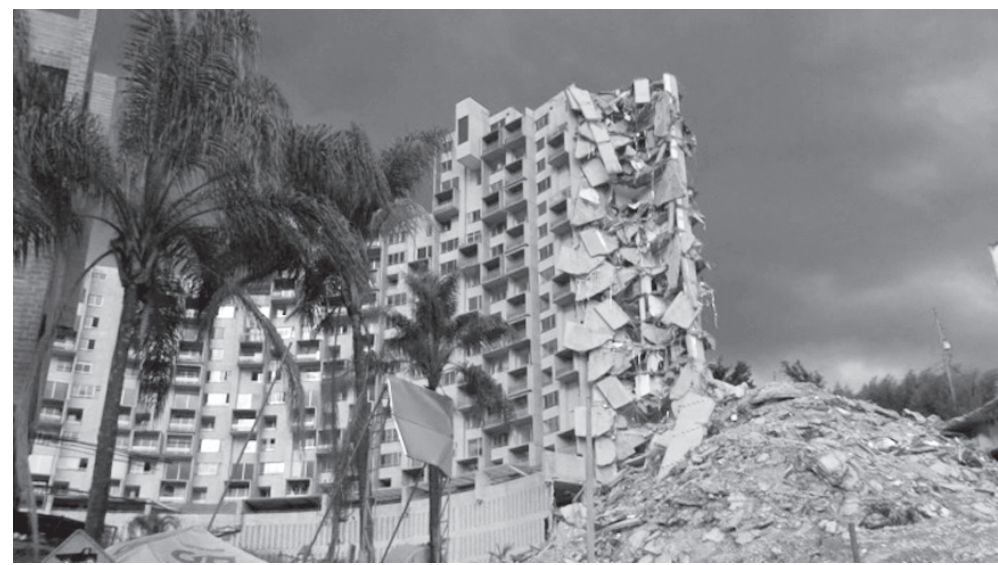

Imagen 3. Vista lateral Edicifio Space luego de su caída (H13N, 2014) 


\section{Proyecto del seguro obligatorio en la construcción de vivienda}

Dada la importancia y trascendencia que para los colombianos tiene la vivienda, bajo la premisa que la actividad de la construcción como actividad peligrosa que es, es altamente reglada y en el día a día propende por alcanzar los máximos niveles de calidad en el diseño y construcción de sus productos, para que no se presenten hechos tan desafortunados como el ya citado de Space en Medellín, Campoalegre en Barranquilla y otros; a fin de garantizar a través de un tercero -la Compañía Aseguradora- a los compradores de vivienda la protección a su patrimonio en caso que ocurra un hecho relacionado con la construcción después de la entrega del inmueble, y para complementar el sistema de garantías y responsabilidad legal definidos en el ordenamiento jurídico colombiano, así como a los productos inmobiliarios que a la fecha existen en el mercado y que son de voluntaria adquisición.

De dicha forma se propuso al Congreso de Colombia, mediante el proyecto de ley Número 111 de 2014, la adopción de una ley por la que se imponga a los constructores de vivienda nueva, la obligación de constituir un seguro contra todo riesgo expedido por una aseguradora legalmente habilitada por la Superintendencia Financiera de Colombia, que por el lapso de 10 años, ampare los perjuicios patrimoniales o materiales que causen estos como consecuencia de la responsabilidad civil-contractual o extracontractual- en que aquellos incurran por causa de las actividades desarrolladas dentro del giro ordinario de sus negocios. Estará expresamente incluida dentro de las coberturas del seguro al que se refiere la presente iniciativa, el diseño, los defectos en la construcción, los materiales, el suelo y la culpa grave del Constructor. Este proyecto finalmente no siguió su curso en el congreso siendo posteriormente archivado.

\section{Ley 1796 de 2016 - Ley de Vivienda Segura:}

El 13 de Julio de 2016 fue sancionada por el presidente de la república la Ley 1796 conocida como Ley de Vivienda segura, cuyo espíritu esencialmente es fijar condiciones para garantizar la calidad de la construcción $\mathrm{y}$ brindar herramientas para proteger adecuadamente a los compradores de vivienda. 
El objeto de la ley puede resumirse en: generar medidas enfocadas a la protección del comprador de vivienda, el incremento de la seguridad de las edificaciones y el fortalecimiento de la función pública que ejercen los curadores urbanos.

En este contexto, la ley se orienta principalmente en 5 aspectos:

a. Revisión independiente de diseños.

b. Supervisión Técnica Independiente.

c. Eliminación de excepciones para no revisar o supervisar proyectos.

d. Fortalecimiento del régimen de responsabilidad de profesionales que participan en el proceso constructivo.

e. Amparo de perjuicios patrimoniales a los compradores de vivienda.

La ley entró en vigencia el 13 de julio de 2016, con excepción del Título IV (Curadores), el cual entrará a regir 1 año después de su promulgación. Sin embargo, existen varios aspectos de la ley que deben ser objeto de reglamentación y que, por tanto, no podrán ser aplicados en la práctica hasta que se expida la reglamentación respectiva.

En lo relacionado con la obligación de cubrir perjuicios patrimoniales por defectos en la construcción existe desde la expedición del Código Civil (artículo 2060) y fue ratificada por el Estatuto del Consumidor y la Ley 1796 de 2016. Ahora bien, la Ley 1796 de 2016 contempla una seria de mecanismos a saber: patrimonio, garantías bancarias, productos financieros o seguros, entre otros para cubrir los perjuicios patrimoniales derivados de defectos en la construcción, los cuales pueden ser elegidos libremente por el obligado a resarcir los perjuicios patrimoniales hasta que el gobierno expida la reglamentación correspondiente, en la que determinará la obligatoriedad de escoger un mecanismo específico en ciertos casos.

Es importante anotar que la obligación de resarcir perjuicios, contenida en la Ley 1796 de 2016 no exime al constructor o enajenador de vivienda de continuar garantizando las obligaciones derivadas del Estatuto del Consumidor. 
Como se indica la Ley 1796 de 2016 hace obligatorio que el constructor debe constituir una garantía para resarcir los perjuicios patrimoniales que sufra el comprador de vivienda por defectos en la construcción, una de dichas posibles garantías es el seguro decenal.

\section{SEGURO DECENAL}

\section{Coberturas}

La cobertura básica del seguro decenal es cubrir los daños materiales causados en el edificio por vicios o defectos que tengan su origen en errores de diseño, deficiencias en la construcción o en los materiales, que afecten a la cimentación, los soportes, las vigas, los forjados, los muros de carga u otros elementos estructurales, y que comprometan directamente la resistencia mecánica y estabilidad del edificio.

\section{Coberturas adicionales}

a. Los costes de reparación y refuerzo en que se incurra para eliminar la amenaza de hundimiento de la obra, y que sean necesarias para salvaguardar la construcción.

b. Los gastos de demolición y desescombro que hayan sido necesarios a consecuencia de los daños materiales de la construcción cubiertos por la póliza.

c. Los daños materiales y personales causados a Terceros y sus perjuicios consecuenciales, siempre que esos daños materiales y personales sean consecuencia directa de un siniestro indemnizable.

\section{Exclusiones}

Las exclusiones más significativas en el seguro decenal pueden resumirse en:

a. Daños ocasionados por mal uso o falta de mantenimiento adecuado de la edificación. Costos de postventa a los que está obligado el contratista para la correcta terminación o acabado de la misma, o para el correcto funcionamiento de la misma. Entre estos están los costos de reparación de goteras, tuberías averiadas, humedades por filtración de aguas. 
b. Daños que sean ocasionados por caso fortuito o fuerza mayor como terremoto, tsunami, erupción volcánica, vientos huracanados, inundación, entre otros.

c. Daños ocasionados por actos de terceros, terrorismo, huelga, motín, asonada, conmoción civil o aquellos ocasionados por el propio perjudicado por el daño.

\section{Generalidades}

Duración de la cobertura: en su amparo básico, período de vigencia de 10 años a partir de entregado del certificado técnico de ocupación, sin que pueda ser cancelada durante el periodo de cobertura.

El Seguro Decenal ampara el costo de reconstrucción total de la edificación (el valor a la fecha de inicio de la vigencia de la póliza).

No hay diferencias en la cobertura en función del tipo de construcción (viviendas individuales, edificios de viviendas en altura, edificios administrativos, complejos industriales, centros comerciales, hospitales, colegios, infraestructura, etc.).

En la póliza de Seguro Decenal daños, comparado con una póliza por RC, la culpa o responsabilidad no necesita demostrarse, ahorrando al reclamante un posible litigio costoso y prolongado.

El valor asegurado para la cobertura de Responsabilidad Civil Extracontractual equivaldrá permanentemente durante la vigencia de la cobertura a un porcentaje del valor asegurado en daños. Este valor puede estar entre el 5 y el 10\% del valor asegurado.

En ningún caso la vigencia del seguro comenzará antes de que la construcción haya recibido el visto bueno y la emisión del certificado técnico de ocupación.

El costo del seguro (prima) varía dependiendo el contenido de la cobertura, las condiciones de operatividad de la póliza (incidencias técnicas) y el tipo de obra/construcción. 
Para efectos de recibir una cotización, el cliente debe proporcionar al asegurador, antes de que comience la obra de construcción, los requisitos para el Seguro Decenal y la información técnica del proyecto.

\section{CONSIDERACIONES SOBRE EL SEGURO DECENAL}

Se ha supuesto que el seguro decenal encarece el valor de un proyecto, en realidad eso no es cierto, el costo en general no es superior al $1 \%$ del valor de obra y, probablemente, en torno a un $0,6 \%$ del valor de venta. Esto no es caro a cambio de diez años de seguridad total ante riesgos imposibles de asumir sin seguro.

Por otro lado, en el momento de querer vender una casa o edificio que no cuente con la protección del seguro decenal muy probablemente su costo será inferior a aquel que si tenga el seguro, lo que al final del ejercicio restituirá al dueño del proyecto prácticamente el costo de la póliza.

\section{GESTIÓN DE LA OCT}

Para la suscripción del seguro decenal se hace necesaria la intervención de un organismo de control técnico, algunos constructores han supuesto que la OCT es un engaño y un cobro más impuesto por la las compañías de seguros. Esto no es cierto, el seguro decenal es un seguro complejo donde hay una fortísima carga técnica y para contar con seguridad acerca de la calidad del proyecto, los cálculos, las mediciones, la adecuación a normativa y la correcta ejecución material las aseguradoras se sirven de terceros de su confianza. Esto no debe generar preocupación en los constructores: simplemente se trata de verificadores que avalan la asegurabilidad de la obra. Una buena OCT da al constructor un complemento profesional que le permite conocer con antelación un posible error de cálculo, diseño o ejecución material y evitar, con ello, el desastre sobre su mayor inversión.

\section{CONCLUSIONES}

La industria de la construcción enfrenta múltiples actividades dinámicas que conllevan a decisiones constantes durante la ejecución de un proyecto. En las partes involucradas como diseño, profesionales de obra, normas y estándares de calidad, el riesgo siempre es y seguirá siendo latente. 
La cobertura para el seguro decenal deja de cierta forma la tranquilidad de trasladar un riesgo que permite brindar hacia el constructor y al comprador de vivienda, eliminar de cierta forma la incertidumbre de riesgo expuesto, pues con esta cobertura de 10 años siguientes a la terminación de la obra deja un parte de conformidad y seguridad en la ejecución y la inversión por parte del comprador.

De otra parte, la nuevas normativas, especialmente la ley 1796 de 2016, debe apuntar a que Colombia este en inmerso a la vanguardia de los países de alto estándar de calidad en materia de construcción y de esta forma mitigar el riesgo al que en los últimos años se ha visto expuesto nuestro país en materia de calidad y ejecución de obra, especialmente en tema de soluciones de vivienda. La oportunidad de entrar al mercado colombiano con este tipo de cobertura, no deja más que la tranquilidad de protección al patrimonio de los constructores y garantizar la calidad de la construcción, en razón al proceso de ejecución que se lleva a cabo desde el inicio de la obra y que es supervisado por el organismo de control técnico especializado, requisito indiscutible de la póliza decenal.

\section{BIBLIOGRAFÍA}

COLPRENSA, B. (23 de Mayo de 2016). Vanguardia . Recuperado el 05 de Marzo de 2017, de Pliego de cargos a curador vinculado en caso de edificio space : http:// www.vanguardia.com/colombia/359473-pliego-de-cargos-a-curador-vinculadoal-caso-del-edificio-space

Dinero, R. (03 de Marzo de 2017). ¿Rebotará el crecimiento? Dinero , 32-33.

Flórez, G. E. (03 de Diciembre de 2016). La dinámica del sector edificador, en manos de la reforma tributaria . El Tiempo .

Flórez, G. E. (25 de Febrero de 2017). Cierre de Tejado. El Tiempo.

H13N. (10 de Junio de 2014). Youtube. Recuperado el 05 de Marzo de 2017, de Recomiendan mantener orden de demolición Edificio Space : https://www.youtube. com/watch?v=iCvTryk0VKs

López, J. L. (25 de Febrero de 2017). Los Impactos Invisibles . El Tiempo, pág. 3.

MEDELLÍN. (30 de Diciembre de 2014). El Tiempo. Recuperado el 05 de Marzo de 2017, de CDO se niega a recibirle el lote de Space a la Alcaldía de Medellín: 
http://www.eltiempo.com/colombia/medellin/polemica-por-lote-del-edificiospace/15031215

Semana, R. (26 de Febrero de 2017). Un nuevo aire . Semana, 80-81.

Space, E. c. (Abril de 2014). Universidad de Los Andes . Recuperado el 05 de Marzo de 2017, de Boletín informativo : http://civil.uniandes.edu.co/Boletin/index. $\mathrm{php} / \mathrm{k} 2 /$ item/33-conceptouniandes

Vivienda, M. d. (15 de Septiembre de 2016). Metro Cuadrado. Recuperado el 05 de Marzo de 2017, de Dane reportó un incremento del 25 por ciento en licencias de construcción : http://www.metrocuadrado.com/decoracion/content/dane-reportoun-incremento-del-25-por-ciento-en-licencias-de-construccion

\section{REFERENCIAS}

Adam,J.-P. 1989. La construction romaine, Editions Picard, Paris.

Carcopino, J. 1939. La Vie quotidienne à Rome à l'apogée de l'Empire, Hachette, Paris.

Chanut, P.-Y. 1991. Les habitations en latin: étude léxicologique, Atelier National de Reproduction des Thèses, Lille.

Choisy, A.1909. Vitruve, Imprimerie-Librairie Lahure, Paris.

Fernández Vega, P.-E. 1999. La casa romana, Akal, Madrid.

Homo, L. 1951. Rome impériale et l'urbanisme dans l'antiquité, Albin Michel, Paris.

Malavé Osuna, B. 2000. Legislación Urbanística en la Roma Imperial. A propósito de una Constitución de Zenón, Universidad de Málaga, Málaga.

Packer, J.-E. 1971. The Insulae of Imperial Ostia, American Academy, Rome.

Saliou, C. 1994. Les lois des bâtiments. Voisinage et habitat urbain dans l'Empire romain. Recherches sur les rapports entre le droit et la construction privée du siècle d'Auguste au siècle de Justinien, Institut Français d'Archéologie du Proche-Orient, Beyrouth.

Storey, G.-R. 2003. "The "Skyscrapers" of the ancient roman world", Latomus: revue d'études latines, Vol. 62, N. 1, pp 3-26.

Publicat fa 29th June 2014 per ARRAONA ROMANA - Etique.

“Publicado por Avante el 22 de junio de 2011 Guardar Post Guardar Comentarios". 
Ministerio de Vivienda- Antecedentes Proyecto de Ley 111 de 2014 "Por la cual se establece la obligación de adquirir un seguro por parte de los constructores de vivienda nueva y se establecen medidas para incrementar la seguridad de las edificaciones".

ABC de la ley 1796 de 2016 - Ministerio de Vivienda.

Durée de la garantie décennale_2010. 